\title{
Contribuições da Extensão Universitária na formação social, acadêmica e profissional dos estudantes de Computação
}

\author{
Juliana Maria Oliveira dos Santos, Cíntia Mercês Souza, Taiala Almeida Santos, \\ Pietro Matheus Bompet Fontoura Alves, Débora Abdalla Santos
}

Departamento de Ciência da Computação - Universidade Federal da Bahia (UFBA) Grupo de Pesquisa e Extensão em Informática, Educação e Sociedade - Onda Digital Av. Adhemar de Barros, s/n - Ondina - CEP 40.170-110 - Salvador - BA - Brasil

\{julyms.85, cintiamercess, taiala25, pietrobompet\}@gmail.com, abdalla@ufba.br

\begin{abstract}
The extension activities at the university, contributes to operationalize the transforming relationship between university and society. The Ação Curricular em Comunidade e em Sociedade (ACCS) has been fulfilling this role, developing extension actions, promoting the exchange, reworking and production of knowledge on computing and society. This article presents the methodologies used for the development of ACCS: Onda Solidária de Inclusão Digital - Tecnologia a Serviço da Cidadania and discusses the impact of this action on social, academic and professional of the student of higher education in computing.
\end{abstract}

Resumo. A extensão, um dos pilares da Universidade, contribui para operacionalizar a relação transformadora entre Universidade e Sociedade. A Ação Curricular em Comunidade e em Sociedade (ACCS) vem cumprindo este papel, desenvolvendo ações de extensão, promovendo o intercâmbio, a reelaboração e a produção de conhecimento sobre a computação e sociedade. Este artigo apresenta as metodologias utilizadas para o desenvolvimento da ACCS: Onda Solidária de Inclusão Digital - Tecnologia a Serviço da Cidadania, bem como discute os impactos desta ação na formação social, acadêmica e profissional do estudante de ensino superior na área de computação.

\section{Introdução}

A Extensão Universitária é entendida como "processo acadêmico definido e efetivado em função das exigências da realidade, além de indispensável na formação do estudante, na qualificação do professor e no intercâmbio com a sociedade" [FORPROEX, 2012, p. 05]. As Diretrizes Curriculares de cursos da área de Computação e Informática estabelecem que "no contexto de uma formação superior, há que se considerar a importância de currículos que possam, efetivamente, preparar pessoas críticas, ativas e cada vez mais conscientes dos seus papéis sociais e da sua contribuição no avanço científico e tecnológico do país" [Brasil, 1999]. Porém, na prática, muitos currículos atuais ainda focam em conteúdos predominantemente técnicos e científicos, apesar das responsabilidades organizacionais e culturais que cercam todo profissional, com destaque aqui o profissional de computação que cria aplicações e artefatos que atingem direta ou indiretamente a sociedade, conforme aponta [Jonathan, 2016].

A compreensão acerca do papel das ações extensionistas foi fortalecida, no âmbito da Universidade Federal da Bahia (UFBA), desde 1997, quando da criação do 
Programa UFBA em Campo, atualmente denominado Ação Curricular em Comunidade e em Sociedade (ACCS), iniciativa pioneira nas universidades, que constitui uma experiência de aproximar estudantes e professores da UFBA com grupos da sociedade, desenvolvendo ações de extensão no âmbito da criação, tecnologia e inovação, promovendo o intercâmbio, a reelaboração e a produção de conhecimento sobre a realidade com perspectiva de transformação. Desenvolvem-se numa perspectiva dialética e dialógica, participativa e compartilhada por intermédio de intervenções em comunidades e sociedades, na busca de alternativas para o enfrentamento de problemáticas que emergem na realidade contemporânea. [Pró-Reitoria de Extensão, 2017].

De acordo com a Resolução $\mathrm{n}^{\circ}$ 01/2013 que regulamenta o aproveitamento da ACCS para integralização curricular dos Cursos de Graduação e Pós-Graduação da UFBA, a ACCS é um "componente curricular, modalidade disciplina, que deve assegurar a multidisciplinaridade, a interdisciplinaridade e a transdisciplinaridade pela relação dialética e dialógica entre diferentes campos dos saberes e fazeres necessários para atuação em comunidade e sociedade" [UFBA, 2013, p.1].

O Departamento de Ciência da Computação (DCC) da UFBA, reconhecendo a extensão como uma atividade que possibilita aos seus participantes a descoberta de habilidades e competências, o desenvolvimento técnico e científico e a tomada de consciência social e cidadã, oferece regularmente desde 2009, a ACCS MATC53 Onda Solidária de Inclusão Digital - Tecnologia a Serviço da Cidadania que permite aos estudantes dos cursos de computação, que possuem predominância de componentes curriculares com conteúdos técnicos, quebrar as friezas do mundo digital, preparando o educando para o exercício da cidadania e proporcionando, assim, uma formação profissional integral, atentando para o seu papel social e permeando diversas áreas do conhecimento. Atualmente, a ACCS apoia as atividades do programa permanente de extensão Onda Digital, onde os estudantes universitários atuam como instrutores em capacitações para o uso das Tecnologias Digitais de Informação e Comunicação (TDIC), intercambiando saberes com diversos setores sociais.

Este artigo propõe apresentar as metodologias utilizadas para o desenvolvimento desta atividade, bem como evidenciar os impactos desta na formação social, acadêmica e profissional do estudante de computação e as contribuições que esta atividade provoca nos grupos sociais que são público-alvo. Assim, espera-se contribuir para o ensino da Computação, mostrando novas possibilidades de práticas pedagógicas com articulação interdisciplinar e social na integralização dos currículos de cursos.

O artigo é apresentado da seguinte maneira: a seção 2 descreve a concepção, metodologia e ações desenvolvidas nesta atividade de extensão; a seção 3 descreve os impactos da ação na formação dos estudantes de ensino superior e a seção 4 mostra as conclusões e os trabalhos futuros.

\section{Concepções, Metodologia e Ações desenvolvidas}

A ACCS Onda Solidária de Inclusão Digital - Tecnologia a Serviço da Cidadania foi criada em 2009 com o objetivo de dar apoio às atividades do Programa Onda Digital, buscando promover a troca de conhecimentos acadêmicos sobre as Tecnologias Digitais de Informação e Comunicação (TDIC), especialmente no uso do Software Livre, possibilitando aos estudantes o desenvolvimento de competências relacionadas com a 
aproximação e interação com a comunidade. O desenvolvimento desta atividade permite que estudantes de graduação sejam instrutores, despertando neles a função de estudantes educadores, promovendo assim aproximação entre Sociedade e Universidade.

O Programa Onda Digital (POD) foi criado em 2004, sob a coordenação do Departamento de Ciência da Computação do Instituto de Matemática e Estatística, como um programa permanente de extensão da Universidade Federal da Bahia e tem por missão contribuir com a inclusão sociodigital na Bahia, envolvendo a Universidade em ações educativas e de difusão do Software Livre.

As ações são planejadas de forma colaborativa, incentivando a interdisciplinaridade com o envolvimento de estudantes da UFBA de diferentes unidades de ensino da universidade, estabelecendo assim uma troca extremamente rica de experiências, conhecimentos e vivências na construção de um saber a serviço de uma sociedade com mais oportunidades. Utilizando-se da metodologia de Pesquisa-Ação [Thiollent, 1985), as ações passam por constantes avaliações e aperfeiçoamentos da prática por todos os seus participantes, provocando eventuais mudanças que trazem benefícios para o processo de construção.

O componente curricular é oferecido semestralmente e são abertas, em média, 20 (vinte) vagas, priorizando-se a participação de estudantes dos seguintes cursos: Ciência da Computação, Sistemas de Informação, Licenciatura em Computação, Engenharia da Computação, Bacharelado Interdisciplinar em Ciência e Tecnologia, Pedagogia, Serviço Social, Ciências Sociais, Comunicação e Psicologia. Em caso de sobra de vagas, estudantes de outros cursos podem matricular-se no componente.

Utilizamos recursos computacionais que auxiliam a participação de todos nas decisões, elaboração e avaliação de atividades. Inicialmente, nas seis primeiras edições, utilizamos a ferramenta de desenvolvimento colaborativo de conteúdo na web, a Wiki. Atualmente utilizamos o Ambiente Virtual de Aprendizagem (AVA) Moodle para realização do planejamento e registro das ações desenvolvidas na ACCS. Os participantes dos cursos de extensão promovidos pela ACCS também utilizam o AVA Moodle para acesso ao material didático e discussões, sob a condução dos estudantes educadores que utilizam o ambiente com a função de professor.

Os alunos da ACCS participam de um encontro presencial semanal com duração de 2 (duas) horas onde estudantes educadores, coordenadores, monitores e colaboradores discutem os pontos fortes e fracos da ação, como forma de avaliação das atividades executadas na semana anterior, refletindo e melhorando as práticas pedagógicas, priorizado pela dialogicidade.

Ao todo, 204 estudantes já participaram da ACCS. Desse total, tivemos a participação de apenas dois estudantes de pós-graduação (Mestrado em Ciência da Computação), conforme pode ser visto na Figura 1.

Observamos que na quase totalidade dos semestres em que o componente foi oferecido, obteve-se a participação de estudantes de pelo menos 4 (quatro) cursos diferentes, sendo a maior parte deles pertencentes aos cursos relacionados à computação e tecnologia. Durante o ano de 2014 tivemos duas situações atípicas: no primeiro semestre, a transição do modo de matrícula não foi realizado como previsto e muitos alunos não conseguiram matricular-se; já no segundo semestre por um erro no sistema de matrícula foram ofertadas 40 vagas, o dobro do módulo do componente curricular. 
Embora o componente curricular apresente um histórico diversificado de perfis de alunos com base nos cursos dos alunos matriculados, o número de 204 alunos não necessariamente trata-se de alunos diferentes, visto que é possível matricular-se mais de um semestre neste componente curricular. No entanto, a cada semestre existem propostas de atividades diferentes, estruturadas na sala de aula e executadas em parceria com a comunidade. Desta forma, cada edição proporciona aos seus participantes experiências novas, por vezes em novos espaços, dando oportunidades diversas de crescimento pessoal, profissional e acadêmico. Partindo do fato que as atividades são pensadas de acordo com a disponibilidade e possibilidade de contribuição segundo o perfil de cada participante, então ainda que seja no mesmo local, as contribuições sempre serão diferentes e em uma via de mão dupla.

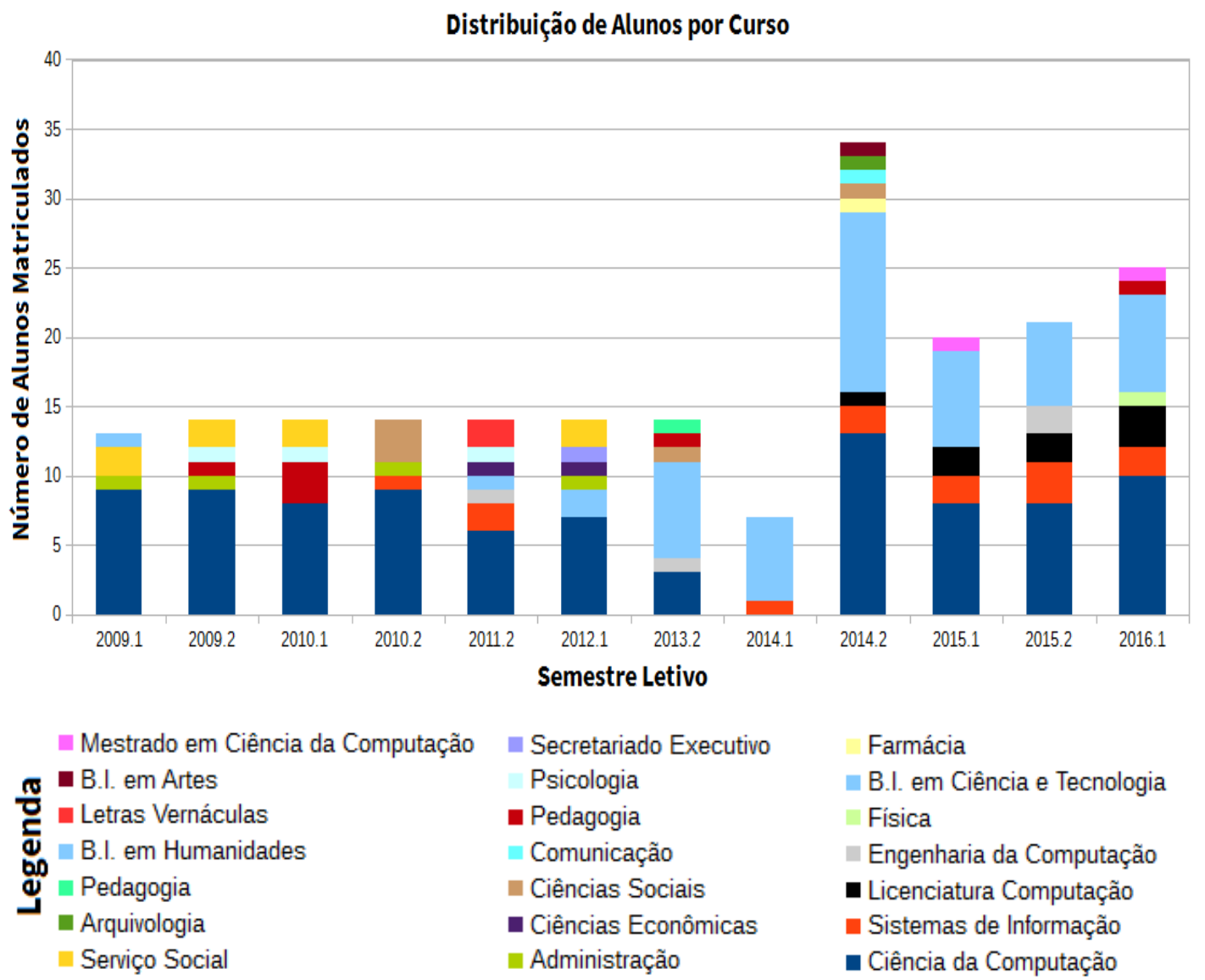

Figura 1. Gráfico da distribuição de alunos por curso e legenda

Estudos recentes [CGI.br e GSMA, 2016] apontam além das disparidades econômicas, sociais e regionais existentes nos países da América Latina e Caribe, a falta de conteúdos localmente relevantes e a falta de competências digitais como barreiras à inclusão digital. Somado a isto, tem-se a falta de infraestrutura das TICs para dar suporte à aprendizagem e apoio à educação digital, impedindo que muitos usuários possam explorar os benefícios que a internet oferece. Apesar da cobertura de banda larga móvel alcançar diversas regiões e do número de smartphones já ter superado o número de computadores nas residências brasileiras, o modelo de inclusão digital brasileiro - que permite que as lojas de aplicativos e os websites de operadoras móveis 
disponibilizem conteúdos relacionados, sobretudo, com o entretenimento - oculta a relevância e o potencial de impacto profundo que a internet e demais TICs podem possibilitar. Partindo desta visão, a ACCS propõe ações de formação que buscam contribuir no processo de desenvolvimento e transformação social com o envolvimento de estudantes de graduação e proposição de conteúdos alinhados com os interesses do público-alvo, considerando as realidades, limitações e peculiaridades das demandas locais de cada comunidade.

Os cursos propostos no âmbito da ACCS aqui tratada são ministrados em laboratórios da universidade ou outros espaços disponibilizados pelas comunidades parceiras, pensando no cenário exposto anteriormente e considerando as diversas realidades e necessidades. Dentre as ações já realizadas, destacamos:

1. Curso de Internet e Tecnologias Abertas: tem como objetivo introduzir os estudantes aos conhecimentos de informática básica e orientar sobre o uso seguro da internet, capacitando-o profissionalmente na utilização dos principais aplicativos de escritório com propósito de aprimorar o uso das tecnologias digitais para formação do perfil desejado de cidadão contemporâneo. Ementa: Familiarização com o sistema operacional livre. Internet: navegadores, buscadores e downloads. Familiaridade com a nuvem e cibersegurança. Fluência em dispositivos móveis. Uso de E-mails. Suíte de Escritório livre LibreOffice: editor de texto, planilha eletrônica e editor de apresentação. Duração: 30 horas

2. Curso de Iniciação à Programação de Computadores: tem como objetivo introduzir alunos de ensino médio ao contexto de programação de computadores, incentivando o desenvolvimento lógico-matemático dos mesmos. Os conteúdos são apresentados de forma lúdica, com a utilização de recursos audiovisuais, dinâmicas e aulas práticas, incentivando o exercício do raciocínio lógico para desenvolvimento da capacidade de compreender problemas, não só computacionais ou matemáticos, mas sim em diferentes áreas e formular soluções. Este curso tem também como objetivo descobrir novos talentos para a área de computação. Ementa: Raciocínio lógico. Algoritmos. Estruturação de dados. Estruturas de controle de linguagens de programação. Implementação de soluções a problemas utilizando ferramentas computacionais voltadas para o ensino de programação. Implementação de soluções a problemas utilizando linguagem de programação. Duração: 30 horas

3. Curso de Montagem e Manutenção de Microcomputadores: tem como objetivo capacitar o estudante a identificar os componentes físicos dos computadores e suas funcionalidades, realizar recondicionamento e montagem de computadores e intervenções no hardware no âmbito da manutenção preventiva e corretiva, além de realizar a instalação de sistemas operacionais e aplicativos. Ementa: Componentes de um computador e suas funcionalidades. Recondicionamento de Computadores. Montagem de computadores. Manutenção Preventiva. Manutenção Corretiva. Detecção de hardware. Instalação de sistema operacional e aplicativos. Apresentação de ferramentas e softwares para gerenciamento e manutenção do sistema. Noções de gestão de negócio. Duração: 30 horas

4. Oficinas Itinerantes: ações de formação que visam a criação de espaços para discussão e aprofundamento de temas que incluam o acesso à informação, o 
futuro da sociedade e a socialização da tecnologia, permitindo a reflexão acerca das interferências dos avanços tecnológicos na sociedade e levando seus participantes a se conscientizarem da importância da apropriação deste conhecimento. Os temas das oficinas incluem: Ativismo Digital, Eleições, Software Livre, Serviços ao Cidadão, Internet Segura, dentre outros. Duração: 2 horas.

5. Oficinas de Informática Básica: oficinas de curta duração que são realizadas em locais que possuem um público rotativo (a exemplo de hospitais) e que não dependem de conhecimento prévio. São exemplos de temas tratados nestas oficinas: criação de e-mail, formatação de texto, produção de slides, pesquisa na internet, etc. Duração: 1 hora.

6. Descarte adequado de lixo eletrônico e recondicionamento de computadores: ações de formação para despertar a responsabilidade ambiental para com o lixo computacional, reaproveitando materiais que antes seriam simplesmente descartados (monitores de computador, teclado, mouse e demais periféricos antigos), transformando-os em outros objetos possíveis de serem utilizados no dia a dia, como utensílios domésticos, peças de decoração artesanais, e brinquedos. Além de incentivar o recondicionamento de computadores, com a instalação de softwares livres, promovendo o prolongamento da vida útil de equipamentos que poderão ser utilizados em espaços públicos de acesso à internet.

Priorizando a realização de ações para crianças, jovens e adultos em situação de vulnerabilidade socioeconômica dos bairros de Salvador e Região Metropolitana, os locais de atuação foram dos mais diversos, possibilitando aos estudantes de graduação conhecer e ter contato com diferentes espaços, crenças, culturas e comunidades, constituindo-se em desafios constantes a serem superados pelos estudantes. Ao longo dos 12 semestres em que a ACCS vêm se desenvolvendo, os estudantes estiveram imersos em diversas comunidades, cada uma com suas peculiaridades: comunidade inserida na cultura africana do candomblé, comunidade rural, crianças com câncer e suas famílias, pessoas surdas, comunidades diretamente inseridas no movimento negro, crianças em situação de privação de liberdade, jovens oriundos da realidade do ensino público, jovens oriundos de bairros carentes, entre outros, totalizando mais de 600 atendidos.

Para vencer o desafio de trabalhar com diversas culturas é imprescindível o envolvimento de professores e estudantes das mais variadas áreas do conhecimento, para que cada um possa dar sua contribuição, de modo a promover uma atuação verdadeiramente interdisciplinar. Assim, a participação de estudantes de graduação desta universidade oriundos das mais diversas áreas de conhecimento com perfis e experiências variadas possibilita que as atividades possuam uma abordagem que vai além do conhecimento instrumental, e possibilita também a observação das situações de pontos de vistas diversificados.

\section{Impactos na formação dos estudantes}

Para [Pinto, Rocha e Vilarim, 2010] ainda existe uma inadequação das práticas pedagógicas atuais para a realidade multidisciplinar, multidimensional, global e contextualizada. $\mathrm{O}$ ensino disciplinar, fragmentado, baseado em informações isoladas e, 
em muitos casos, distante de um contexto mais abrangente não atende mais às exigências do mundo atual, tornando urgente a "necessidade da formação de profissionais que saibam articular conhecimentos oriundos de diversas áreas; indivíduos capazes de avaliar situações/contextos abrangentes de forma crítica e reflexiva; e pessoas habilitadas para produzir soluções/conhecimentos que atendam a diferentes necessidades da sociedade". Neste sentido, os projetos pedagógicos de cursos de graduação em Computação e afins já destacam competências que o estudante deve ser capaz de desenvolver, tais como: pensamento crítico, capacidade de reflexão e autonomia.

A coleta de dados para identificação das contribuições e impactos da ACCS na formação acadêmica, profissional e social dos estudantes foi realizada por meio de questionários e análise documental. Quanto à consciência do seu papel social, destacamos o depoimento abaixo:

"Participar de uma ACCS é uma experiência única que todos os alunos desta Universidade deveriam vivenciar. $O$ trabalho em equipe entre estudantes de cursos de áreas diversas e a interação com a comunidade externa contribuem de maneira significativa para a formação, não só do profissional, mas do cidadão. Poder contribuir ativamente para a inclusão sociodigital daqueles que estão às margens da globalização e, muitas vezes, sem acesso a uma educação de qualidade, além de contribuir com o descarte adequado do lixo tecnológico, nos deixa orgulhosos e com a sensação de estar cumprindo nosso papel social." (estudante de Engenharia da Computação, participação no semestre 2011.2).

A participação nas atividades promovidas pela ACCS tornam possível o exercício real da interdisciplinaridade com a imersão em contextos e realidades diferentes daquelas já vivenciadas, além do contato com crenças e culturas desconhecidas por alguns. As diversas situações que podem emergir da prática possibilitam ao estudante desconstruir tabus e preconceitos, identificar desafios e obstáculos e tomar decisões e posturas para resolução de conflitos e frustrações. Apresentamos alguns depoimentos que apontam para essa característica:

"A experiência de viver uma ACCS foi única, trabalhamos em comunidades muito carentes, parecidas com a que moro. Para mim apresentar minha realidade para colegas da academia que nunca havia pegado um onibus na vida foi ímpar, principalmente quando eles se vêem como atores e autores na atividade fora da Universidade com tantos contrastes culturais e sociais mesmo vivendo na mesma cidade foi notório o choque. Isso me fez crescer acadêmico, pessoal $e$ profissionalmente. Eu sou uma daquelas pessoas que conseguiu romper essa barreira sociocultural e ser a interface entre os dois mundos, sonhando com o dia em que essa figura mediadora não será mais necessária." (estudante de Ciência da Computação, participação no semestre 2011.2)

Observamos que os impactos das atividades realizadas influenciam além dos alunos dos cursos de computação, a exemplo do depoimento abaixo dado por uma aluna do curso de Serviço Social:

"Bem, o que posso dizer é que essa experiência foi muito enriquecedora para mim em todos os sentidos, e quando digo isso não me refiro somente ao campo profissional, mas também ao campo pessoal, a minha formação enquanto pessoa humana. Neste projeto pude amadurecer muito e ter uma visão mais apurada de 
problemas cotidianos que poderei enfrentar enquanto uma profissional, que estará atuando principalmente sobre os impactos causados pelas desigualdades sociais, que de fato sabemos que existem, mas que muitas vezes na correria do dia-a-dia não nos damos conta ou não temos uma ação mais efetiva que demonstre a nossa preocupação frente a essas problemáticas." (estudante de Serviço Social, participação no semestre 2011.2)

No que concerne à frustração pelo resultado do trabalho desenvolvido não ser o esperado, ou até mesmo por não ter conseguido efetivar o planejado, temos o depoimento de um estudante de Psicologia: "Devo considerar que o processo educativo em condições estruturais precárias é assim, num dia se avança e noutro sente-se um retrocesso, mas sigo pra frente, fazendo o meu trabalho da melhor forma que posso, querendo ardentemente que ele seja reflexo para uma mudança positiva na subjetividade da garotada que ali está." (estudante de Psicologia, participação no semestre 2011.2)

Durante a prática, os estudantes de graduação no papel de facilitador, por vezes se veem desafiados em passar o conhecimento, não sendo tão técnico e pensando nas dimensões humanas, pois o público que está sendo atendido nem sempre conhece determinados termos que para estudantes de Computação são considerados simples, por já estar enraizado no seu cotidiano.

"A dificuldade que tivemos foi com a explicação dos conceitos apresentados durante a aula, porque precisávamos dar as explicações de uma forma simples mas acabávamos entrando em um nível mais técnico. Apesar disto, os demais colegas percebiam que estava encaminhando para um nível mais técnico e chamava atenção do que estava falando. A cooperação entre os instrutores foi essencial para contornar as dificuldades apresentadas neste primeiro encontro. Haverá reuniões para discutir e aperfeiçoar as aulas para as próximas semanas." (equipe de instrutores do Curso de Iniciação à Programação de Computadores, participação no semestre 2014.2).

"Participar desta atividade foi sem sombras de dúvidas muito enriquecedor para minha formação pessoal e social. Conhecer a realidade de pessoas da população baiana menos favorecidas me fez perceber o tanto de dificuldades que permeiam a sociedade. Desde dificuldades em função do sistema educacional brasileiro precário até dificuldades financeiras. Perdi as contas de quantas vezes alunos dos cursos entraram em contato pra dizer que não iam ou não foram para uma aula por falta de dinheiro de passagem. Isso choca e nos faz refletir que a realidade é muito mais do que a gente pensa que conhece. Pra mim às vezes era difícil passar o conhecimento de forma mais simples, lúdica e didática, mas o apoio dos colegas de equipe, principalmente àqueles que são de outra área do conhecimento ou que já tinham experiência como instrutor de cursos e trabalho comunitário foi essencial para melhorar neste quesito. Até mesmo ver as dificuldades de algumas pessoas em utilizar alguns softwares ou localizar recursos me fez refletir sobre o meu papel enquanto desenvolvedora de sistemas que atenderão aos mais diversos perfis." (estudante de Sistemas de Informação, participação no semestre 2015.2)

Ainda que a extensão seja vista como um processo de objetivos filantrópicos como apontado no trabalho de [Neto, Eliseo, Silva e Pacheco, 2009] sobre a percepção dos estudantes em participar de atividades de extensão, almejamos que as atividades de extensão promovam a autonomia dos envolvidos, sejam eles instrutores e/ou alunos, por 
meio de atividades em que a participação dos educandos seja de maneira ativa, onde haja interação entre as diferentes partes do processo educativo como proposto por [Freire, 1983].

\section{Conclusões}

A Ação Curricular em Comunidade e em Sociedade (ACCS) possibilita aos estudantes de ensino superior, de qualquer área do conhecimento, uma experiência prática do papel de um educador através de um processo enriquecedor, onde ele ensina e também aprende. Para investigar a importância das ações de extensão desenvolvidas na ACCS para a formação social, acadêmica e profissional dos estudantes de graduação, bem como refletir sobre os acertos e oportunidades de melhoria da proposta, estes estudantes, em conjunto com professores e monitores da ACCS discutem e refletem sobre a metodologia adotada, fazendo sugestões, críticas e elogios, tanto presencial quanto virtualmente. Além disso, ao final de cada ciclo, alunos do componente curricular e também os alunos dos cursos de extensão, respondem um questionário avaliando as atividades desenvolvidas e o desempenho dos atores envolvidos.

Dentre as melhorias já realizadas podemos destacar o aumento dos encontros semanais para discussão e reflexão da ação de uma para duas horas. Esta medida, sugerida por uma das alunas de graduação, possibilitou realizar os debates de cada atividade de forma mais calma e reflexiva, com maior retorno dos instrutores em relação ao progresso dos alunos dos cursos de extensão. Outra medida adotada é o fortalecimento das capacitações realizadas para os novos instrutores de cada semestre promovendo o contato destes com instrutores de semestres anteriores para que haja uma interação maior das experiências vivenciadas, no planejamento dos cursos, execução das aulas, desenvoltura e postura perante os alunos. Nos dois últimos semestres os materiais didáticos passaram a ser desenvolvidos em plataformas colaborativas online de modo a facilitar o acesso e permitir ajustes, adaptações e atualizações dos materiais de forma mais dinâmica, bem como obter um histórico das modificações feitas pelos instrutores.

Com o objetivo de proporcionar atividades de maior qualidade, com resultados satisfatórios e disseminar as ações desenvolvidas, algumas oportunidades de melhoria já foram identificadas:

- Publicação dos materiais didáticos confeccionados sob a licença Creative Commons para que grupos interessados em popularizar a ciência, tecnologia e softwares livres possam utilizá-los;

- Acompanhamento do estado psicológico dos instrutores envolvidos nas atividades, principalmente aqueles que realizam atividades com um público que requer cuidados adicionais;

- Ampliação o número de aulas semanais dos cursos de extensão, visto que é uma solicitação recorrente dos alunos participantes dos cursos para que ocorram mais práticas e encontros;

- Elaboração de cartilha de apoio aos instrutores com orientações simplificadas e objetivas da metodologia adotada no trabalho, para facilitar o desenvolvimento das atividades por novos instrutores e tornar a fase de adaptação mais rápida.

Diante das diretrizes e recomendações curriculares sobre a importância e necessidade de uma formação humanística e social aos estudantes egressos dos cursos de Computação e dos relatos de estudantes mostrando o quão benéfico é participar de atividades que possibilitam uma rica troca de experiências, aprendizados e 
conhecimentos entre Universidade e Sociedade, enxergamos que as práticas de ensino engessadas - muito focadas em conhecimentos técnico e científico - devem ser revistas, pois apesar de necessários para o exercício profissional, estes conhecimentos devem atuar em conjunto com outras habilidades formando, assim, o perfil do profissional do mundo contemporâneo, um profissional que seja capaz de tomar decisões e criar soluções de maneira rápida e preparado para atuar de maneira holística, levando em consideração aspectos culturais, políticos, econômicos e sociais envolvidos.

\section{Referências}

Brasil. (1999) Ministério da Educação. Secretaria de Educação Superior. Diretrizes Curriculares de Cursos da Área de Computação e Informática, http://www.inf.ufrgs.br/ecp/docs/diretriz.pdf

CGI.br (2016). Comitê Gestor da Internet no Brasil. TIC Domicílios 2015: Pesquisa sobre o uso das tecnologias de informação e comunicação nos domicílios brasileiros, http://cetic.br/media/docs/publicacoes/2/TIC_Dom_2015_LIVRO_ELETRONICO.p df, Março

FORPROEX. (2012) Fórum de Pró-Reitores de Extensão das Universidades Públicas Brasileiras. Política Nacional de Extensão Universitária, https://www.ufmg.br/proex/renex/images/documentos/2012-07-13-PoliticaNacional-de-Extensao.pdf, Março.

FREIRE, Paulo. Extensão ou comunicação? $7^{\mathrm{a}}$ ed. Rio de Janeiro, Paz e Terra, p. 93 (O Mundo, Hoje, v.24). 1983

GSMA. (2016) Connected Society: Digital inclusion in Latin Americaand the Caribbean, http://www.gsma.com/latinamerica/pt-br/inclusao-digital, Março 2017

Jonathan, M. (2016) Currículos de Computação: porque permanecem assim? In: WEI $24^{\circ}$ Workshop sobre Educação em Computação - XXXVI Congresso da SociedadeBrasileira de Computação, http://ebooks.pucrs.br/edipucrs/anais/csbc/assets/2016/wei/06.pdf, Março

Neto, J. S.O., J. S.; Eliseo, M. A. ; Silva, L. A. ; Pacheco, B. (2009) c. In: XXIX Congresso da Sociedade Brasileira de Computação (SBC) - Workshop em Educação em Informática (WEI), 2009, Bento Gonçalves. XXX Congresso da Sociedade Brasileira de Computação, p. 509-518.

Pinto, C. L. Q; Rocha, C. R. C; Vilarim, G. (2010) Desafios da Prática da Interdisciplinaridade em Cursos de Ciência da Computação: a Experiência do UNIFESO. XXX CSBC, WEI, Belo Horizonte, http://www.inf.pucminas.br/sbc2010/anais/pdf/wei/st05_02.pdf, Março

Pró-Reitoria de Extensão. Ação Curricular em Comunidade e em Sociedade (ACCS). Disponível em: https://proext.ufba.br/accs, Maio

Thiollent, M. (1985) Metodologia da Pesquisa-Ação. São Paulo: Cortez

UFBA. Conselho Superior de Ensino, Pesquisa e Extensão. Resolução nº 01, de 2013.

Disponível em: http://www.contabeis.ufba.br/fcc/wpcontent/uploads/2017/04/ACCS_Resolu\%C3\%A7\%C3\%A3o-01.2013_.pdf, Maio 